\title{
Functional Genomics of Tick \\ Thioester-Containing Proteins Reveal the Ancient Origin of the Complement System
}

\author{
Veronika Buresova $^{\mathrm{a}}$ Ondrej Hajdusek ${ }^{\mathrm{a}, \mathrm{b}}$ Zdenek Franta ${ }^{\mathrm{a}}$ Gabriela Loosova ${ }^{\mathrm{a}}$ \\ Lenka Grunclova $^{a}$ Elena A. Levashinab ${ }^{b}$ Petr Kopacek ${ }^{a}$ \\ anstitute of Parasitology, Biology Centre, Academy of Sciences of the Czech Republic, Ceske Budejovice,

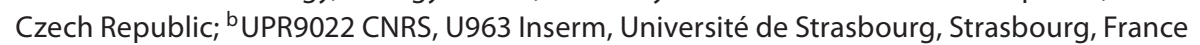

\author{
Key Words \\ Complement $\cdot$ Hemocyte $\cdot$ Ixodes $\cdot \alpha_{2}$-Macroglobulin . \\ Phagocytosis $\cdot$ RNA interference $\cdot$ Thioester-containing \\ proteins $\cdot$ Tick
}

\begin{abstract}
Ticks are important ectoparasites and vectors of multiple human and animal diseases. The obligatory hemophagy of ticks provides a formidable route for parasite transmission from one host to another. Parasite survival inside the tick relies on the ability of a pathogen to escape or inhibit tick immune defenses, but the molecular interactions between the tick and its pathogens remain poorly understood. Here we report that tick genomes are unique in that they contain all known classes of the $\alpha_{2}$-macroglobulin family $\left(\alpha_{2} M-F\right)$ proteins: $\alpha_{2}$-macroglobulin pan-protease inhibitors, C3 complement components, and insect thioester-containing and macroglobulin-related proteins. By using RNA interferencemediated gene silencing in the hard tick Ixodes ricinus we demonstrated the central role of a C3-like molecule in the phagocytosis of bacteria and revealed nonredundant functions for $\alpha_{2} \mathrm{M}-\mathrm{F}$ proteins. Assessment of $\alpha_{2} \mathrm{M}-\mathrm{F}$ functions in a single organism should significantly contribute to the general knowledge on the evolution and function of the com-
\end{abstract}

(C) 2011 S. Karger AG, Basel

1662-811X/11/0036-0623\$38.00/0

Fax +41613061234

E-Mail karger@karger.ch

www.karger.com
Accessible online at: www.karger.com/jin plement system. Importantly, understanding the tick immune mechanisms should provide new concepts for efficient transmission blocking of tick-borne diseases.

Copyright $\odot 2011$ S. Karger AG, Basel

\section{Introduction}

Ticks are blood-feeding ectoparasites (Chelicerata, Arachnida) and vectors of a variety of pathogens (viruses, bacteria, fungi and protozoa) that pose serious health and socioeconomical problems [1]. Ticks of the genus Ixodes are three-host species, where all stages (larva, nymph and adult female) feed on a different vertebrate host and contribute to the pathogen transmission [2]. The feeding is a slow process, taking from a few days (larvae and nymphs) to more than a week in adults. Before the adult female drops off the host, it consumes more than half a milliliter of blood, which accumulates in numerous gut diverticulae. The excess of ingested fluid is continuously excreted from the gut by the midgut cells into the hemolymph, re-

V.B. and O.H. contributed equally to this work. 
absorbed by the salivary glands and secreted back into the host wound [2].

Resistance to starvation and desiccation, long-lasting feeding and intracellular type of blood digestion in ticks offer an exceptionally favorable environment for pathogen proliferation and transmission. For instance during feeding, Borrelia spirochetes, the causative agents of Lyme disease, rapidly multiply in the tick gut lumen. After having crossed the midgut cells by as yet unknown mechanisms, they disseminate in the hemolymph and eventually reach the salivary glands, the strategic site for vertebrate infection [3]. Transmission of an intracellular bacterium of the genus Anaplasma [4] or of the apicomplexan protozoa of the genera Babesia [5] and Theileria [6] begins with the initial infection of the midgut cells and proceeds to the invasion of other tick tissues, including the salivary glands. In all cases, invading pathogens have to overcome tick immune responses, which constitute a critical point of the tick-pathogen interface. In spite of the recent advances [7], our understanding of the tick immune system still remains fragmentary. Sequencing of the first chelicerate genome of the deer tick Ixodes scapularis [8] and feasibility of RNA interference (RNAi) $[9,10]$ offer a unique opportunity to decipher the components of the immune system in ticks and to investigate the interplay between ticks and pathogens at the molecular level.

Proteins of the $\alpha_{2}$-macroglobulin family $\left(\alpha_{2} \mathrm{M}-\mathrm{F}\right)$ are key constituents of the innate immunity of vertebrate as well as invertebrate animals. This evolutionarily conserved family comprises (1) $\alpha_{2}$-macroglobulins $\left(\alpha_{2} \mathrm{Ms}\right)$, (2) C3/C4/C5 components of the complement system, and (3) thioester-containing proteins (TEPs) [11]. $\alpha_{2} \mathrm{M}$ pan-protease inhibitors are abundantly present in the plasma of a variety of metazoan organisms and are believed to contribute to the immune defenses by regulating immune responses and guarding the organisms against the proteolytic attacks of invading pathogens [12]. The complement system is activated in vertebrates by the lectin, classical or alternative pathways that lead to the proteolytic cleavage of the $\mathrm{C} 3$ molecule that opsonizes pathogens for phagocytosis or killing through a lytic pore formation [13]. Insect TEPs opsonize various classes of pathogens to promote their phagocytosis and killing [14, 15]. For example, TEP1 from the malaria mosquito Anopheles gambiae binds to and mediates killing of Plasmodium ookinetes in the mosquito midgut $[16,17]$.

Two $\alpha_{2} \mathrm{M}$ protease inhibitors have been previously characterized in two tick species - Ornithodoros moubata (TAM) [18, 19] and Ixodes ricinus (IrAM) [20]. These proteins are synthesized as large precursors and become functional upon proteolytic cleavage of the highly variable segment located within the central part of the molecule [21]. The cleavage induces a rapid conformational change leading to the exposure of the reactive thioester (TE) bond and entrapping the proteases in a macromolecular cage. Interestingly, the RNAi-based functional study of IrAM demonstrated an important role of this molecule in the phagocytosis by hemocytes of the tick pathogen Chryseobacterium indologenes [20, 22].

Here, guided by the tick genome information available in VectorBase, we performed a functional analysis of the $\alpha_{2} \mathrm{M}-\mathrm{F}$ in I. ricinus. We show that the tick genome encodes nine members representing all major groups of $\alpha_{2} \mathrm{M}-\mathrm{F}$. Until now, all groups of $\alpha_{2} \mathrm{M}-\mathrm{F}$ proteins have never been observed in a single organism. RNAi silencing of the newly identified genes revealed their nonredundant roles in the phagocytosis of Gram-negative bacteria. These results provide new insights into the evolution of innate immunity and could shed light on the origin and function of the complement system in animals.

\section{Materials and Methods}

\section{Biological Material}

Adult females and males of $I$. ricinus were collected in Ceske Budejovice in the Czech Republic. For all experiments, 25 females were fed in the presence of the same number of males for 5 days (semi-engorged females) on laboratory guinea pigs. Experimental animals were treated in accordance with the Animal Protection Law of the Czech Republic No. 246/1992 Sb., ethics approval No. $137 / 2008$.

\section{Tissue Dissection and Isolation of RNA}

Tick hemolymph was collected from the wound made by cutting the front leg and used for individual phagocytic assays or RNA isolation. Tissues (guts, salivary glands and ovaries) were dissected on a wax-filled Petri dish. Total RNA was isolated using NucleoSpin RNA II kit (Macherey-Nagel).

\section{Database Search and Phylogenetic Analysis}

Genes coding for I. scapularis TE proteins were identified in the VectorBase (http://iscapularis.vectorbase.org) using both the 0.5 and 1.1 versions of the genome. Phylogenetic analysis was done as described before [23]. For the sequence alignment, regions of about 550 amino acids spanning the central $\alpha_{2} \mathrm{M}-\mathrm{F}$ domain (pfam00207) and TE-containing domain (cd02897) were used.

\section{RT-PCR Profiling}

Total RNA $(0.5 \mu \mathrm{g})$ was reverse-transcribed into cDNA using Transcriptor High Fidelity cDNA Synthesis Kit (Roche). For RTPCR, tick $\alpha_{2} M-F$ sequences were amplified with gene-specific primers or primers derived from $I$. scapularis sequences (online suppl. table S1, text S1; for all online suppl. material, see www. karger.com/doi/10.1159/000328851). Actin (AJ889837) served as a loading control. 


\section{RNAi Silencing}

DNA fragments of tick $\alpha 2 \mathrm{M}-\mathrm{F}$ genes (186-574 bp) were amplified with gene-specific primers or primers derived from I. scapularis sequences (online suppl. table S1, text S1). Primers contained $A p a \mathrm{I}$ and $\mathrm{XbaI}$ restriction sites for further cloning into the pll10 vector with two T7 promoters in reverse orientation, and the dsRNA synthesis was performed as described previously [14]. The dsRNA $(0.5 \mu \mathrm{l}, 3 \mu \mathrm{g} / \mu \mathrm{l})$ was injected into the hemolymph of unfed female of $I$. ricinus using a micromanipulator (Narishige). Control ticks were injected with the same volume of dsGFP synthesized under the same conditions from linearized plasmid pll6 [14]. After $24 \mathrm{~h}$ of rest in a humid chamber, ticks were fed on guinea pigs. At least two independent RNAi experiments were performed for each IrAM knockdown. The efficiency of each dsRNA was tested by RT-PCR and/or Western blotting (data not shown).

\section{Cultivation of Bacteria}

C. indologenes was cultivated in LB medium containing ampicilin $(50 \mu \mathrm{g} / \mathrm{ml})$. Escherichia coli (strain SBS 363) and Staphylococcus aureus were cultivated in LB medium without antibiotics. All cultivations were done in an orbital shaker at $37^{\circ} \mathrm{C}$. The overnight cultures $(2 \mathrm{ml})$ were diluted with 5 volumes of fresh LB medium, incubated for another $2 \mathrm{~h}$ to reach about $10^{9}$ colony-forming units $/ \mathrm{ml}$, centrifuged at $3,500 \mathrm{~g}$ for $10 \mathrm{~min}$, and finally washed 2 times in L15 medium supplemented with $10 \%$ bovine fetal serum (L15-BOFES). Spirochetes of Borrelia burgdorferi (strain CB 53) were cultivated in BSK-H Complete Medium (Sigma) as described before [20].

\section{Phagocytic Assay and Methylamine Treatment}

In vitro phagocytic assays were performed as described previously [20]. Briefly, hemolymph collected from about 25 semi-engorged females was mixed with L15-BOFES medium. For the methylamine treatment assay, L15-BOFES medium was pre-mixed with $0.2 \mathrm{M}$ methylamine or $0.2 \mathrm{M} \mathrm{L}$-glycine (mock control). Hemocytes $\left(4 \times 10^{4}\right)$ within the hemolymph were allowed to adhere to the surface of a round microscope cover slip for $1 \mathrm{~h}$. Then, 100 $\mu l$ of the bacterial suspension in L15-BOFES was added and incubated for $1 \mathrm{~h}$ at $28^{\circ} \mathrm{C}$. Finally, slides were fixed with $4 \%$ formaldehyde, washed in $0.3 \%$ PBS-Tween 20 , and blocked with $1 \%$ BSA and $10 \%$ goat serum. The phagocytosis of bacteria was detected by indirect immunofluorescence using rabbit antibodies against bacteria [22]. For each experiment, the phagocytic index was determined for at least 5 individual slides by counting the number of hemocytes with engulfed bacteria for a total of 100 hemocytes in the microscopic field. Resulting numbers were related to the average phagocytic index obtained for the $d s G F P$ control taken as $100 \%$ in the respective experiment and expressed as relative phagocytosis.

\section{Results}

The Genome of I. scapularis Contains Nine Members of $\alpha_{2} M-F$

To identify $\alpha_{2} \mathrm{M}-\mathrm{F}$ members in ticks, we screened in silico the genome of I. scapularis and identified 9 genes coding for putative TEPs (IsAM1-9) (online suppl. table
S2). Exon-intron structures of IsAM7 and IsAM9 were predicted using the GenScan software (http://genes.mit. edu/GENSCAN.html) and confirmed by sequencing of the corresponding regions from I. ricinus $\mathrm{cDNA}$ (online suppl. text S1).

Phylogenetic analysis across the conserved $\alpha_{2}$-macroglobulin family domain (pfam00207) and TE-containing domain (cd02897) clustered the identified tick $\alpha_{2} \mathrm{M}-\mathrm{F}$ proteins into 4 groups: (1) $\alpha_{2}$ Ms (IsAM1, 2, 4); (2) C3/ C4/C5 complement-like factors (IsAM5, 6, 7); (3) TEP (IsAM3), and (4) macroglobulin complement-related proteins (MCRs; IsAM8, 9) (fig. 1a). This classification was further supported by characteristic domain arrangements (fig. 1b). All tick $\alpha_{2}$ M-F proteins, except for IsAM2 and IsAM8, possessed a conserved TE site. IsAM5, 6 and 7 contained a putative anaphylatoxin and a C-terminal netrin-like (NTR)/complement C345C domain characteristic for vertebrate $\mathrm{C} 3 / \mathrm{C} 4 / \mathrm{C} 5$ complement components. IsAM9 harbored a low-density lipoprotein receptor class A (LDLa) domain, which had been previously found in several insect TEPs. As the first protein with this domain was referred to as MCR [24], we called this group $\alpha_{2}$ M-F MCR proteins. Guided by these data, we renamed the individual tick genes according to their group classification within the $\alpha_{2} \mathrm{M}-\mathrm{F}$ as follows: $A_{2} M 1,2^{\circ}, 3$ (IsAM1, 2, 4); C3-1, -2, -3 (IsAM5, 6, 7), TEP (IsAM3), and MCR1', $2(I s A M 8,9)$ (the circlets indicate proteins without conserved TE, see online suppl. table S1).

\section{Structural Features of the Tick $\alpha_{2} M-F$ Proteins}

Based on the provisional genome sequence data, we made initial structural predictions for the tick $\alpha_{2} \mathrm{M}-\mathrm{F}$ members. Posttranslational cleavage within the argininerich motif of the linker region next to the anaphylatoxin domain is a typical feature of vertebrate $\mathrm{C} 3$-complement molecules. The proteolysis splits the molecule into $\alpha$ - and $\beta$-chains, which are held together by the intramolecular disulfide bridges. We identified similar motifs in the protein sequences of two tick C3-like molecules: C3-2 and C3-3. Interestingly, similar lysine-arginine cleavage motifs were also found in $\mathrm{A}_{2} \mathrm{M} 1, \mathrm{~A}_{2} \mathrm{M} 2^{\circ}$, and TEP (online suppl. table S2; fig. 1b). The corresponding region of C3-1 was missing in the genome sequence and, therefore, could not be analyzed (online suppl. table S2; fig. 1b).

Another important feature of the $\alpha_{2} \mathrm{M}-\mathrm{F}$ is the presence of a catalytic residue located approximately 115 amino acids downstream of the TE site. An amino acid in this position often determines binding specificity of the TE [25]. For instance, in vertebrate $\mathrm{C} 3$ and $\mathrm{C} 4 \mathrm{com}$ plement proteins this position is occupied by a histidine, 
Fig. 1. Phylogenetic tree and domain organization of selected $\alpha_{2} \mathrm{M}$ family proteins. Ixodes scapularis $\alpha_{2} \mathrm{M}-\mathrm{F}$ proteins cluster into four $\alpha_{2} \mathrm{M}-\mathrm{F}$ groups $\left(\alpha_{2} \mathrm{M}, \mathrm{C} 3 / \mathrm{C} 4 / \mathrm{C} 5\right.$ complement, TEP and MCR groups) and possess conserved domain architecture with other invertebrate or vertebrate $\alpha_{2} \mathrm{M}$ $\mathrm{F}$ proteins. a Unrooted phylogenetic tree reconstructed using the neighbor joining (NJ) method based on alignment of about 550 amino acid sequences spanning the conserved $\alpha_{2}$-macoglobulin (pfam00207) and TE-containing (cd02897) domains using ClustalX. Alignment and sequence descriptions are provided as supporting information (online suppl. text S2). Homo sapiens (Hu), Mus musculus (Mo), Cyprinus carpio (Carp), Ixodes ricinus (Ir), Ornithodoros moubata (Om), Limulus sp. (Li), Carcinoscorpius rotundicauda (Cr), Anopheles gambiae (Ag) and Drosophila melanogaster $(\mathrm{Dm})$ are shown. Sequences of $I$. scapularis are emphasized by ovals. The circlets indicate absence of TE bond. Numbers at the branches represent bootstrap support values calculated using the NJ criterion with 1,000 replicates. Scale bar $=0.1$ substitutions per site. b The upper panel shows the domain organization of putative I. scapularis $\alpha_{2} \mathrm{M}-\mathrm{F}$ proteins. The middle panel shows the conserved domain organization of $\mathrm{A}_{2} \mathrm{M} / \mathrm{TEP}$ proteins and additional domains of $\mathrm{C} 3 / \mathrm{C} 4 / \mathrm{C} 5$ complement and MCR proteins. Domain abbreviations and nomenclature are according to the NCBIconserved domain database (http://www. ncbi.nlm.nih.gov/cdd). A2M_N = MG2 (macroglobulin) domain of $\alpha$-2-macroglobulin; A2M_N_2 $=\alpha-2$-macroglobulin family $\mathrm{N}$-terminal region; ANATO = anaphylatoxin homologous domain; LDLa = low-density lipoprotein receptor class A domain; A2M $=\alpha-2$-macroglobulin family; A2M_comp = A-macroglobulin complement component; $\mathrm{A} 2 \mathrm{M}$ _recep $=\mathrm{A}$ macroglobulin receptor; NTR_complement_C345C $=$ NTR/C345C domain. $H$. sapiens $(\mathrm{Hu})$, A. gambiae (Ag) and D. melanogaster (Dm) are shown. The lower panel shows domain organization of invertebrate or vertebrate representatives of each $\alpha_{2} \mathrm{M}-\mathrm{F}$ group. Scissors indicate putative posttranslational cleavage sites. Dots indicate sequence gaps. Asterisks indicate putative TE sites. Lengths of sequences and positions and sizes of individual domains are in scale. Scale bar $=100$ amino acids.

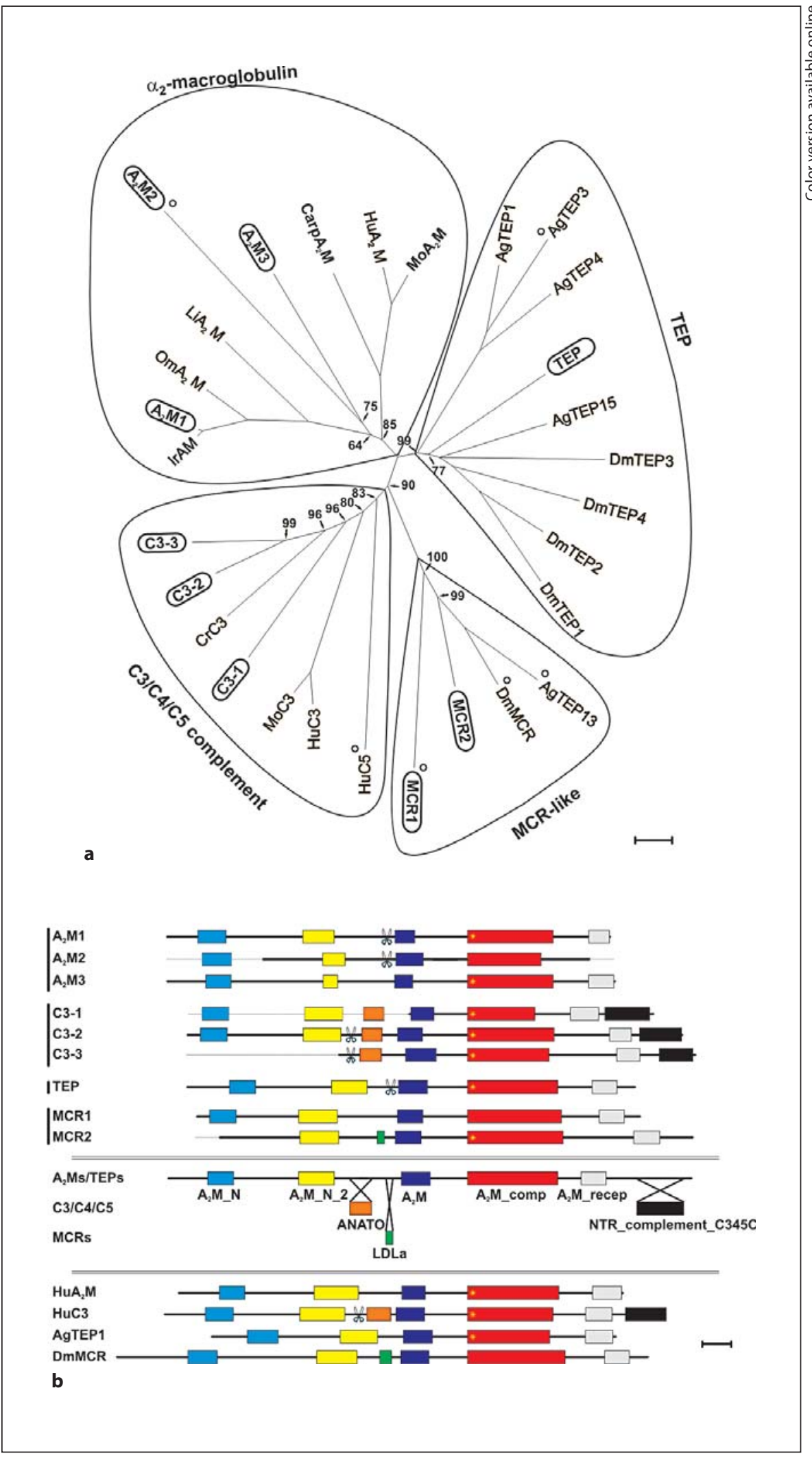


which catalyses binding of TE to the hydroxyl groups (for example, sugars on the microbial surface). Similarly, all three tick C3-related molecules (C3-1, C3-2, C3-3) possessed a histidine at this catalytic site. Substitution at this position by a less nucleophilic residue redirects the TE binding specificity towards the amino groups and leads to the formation of a $\gamma$-glytamyl- $\varepsilon$-lysyl bond, for instance between $\alpha_{2} \mathrm{M}$ and an entrapped protease [26]. In the tick $\mathrm{A}_{2} \mathrm{M} 3$, as in the majority of other $\alpha_{2} \mathrm{M}$, this catalytic site is occupied by an asparagine. However, in $\mathrm{A}_{2} \mathrm{M} 1$ and $\mathrm{A}_{2} \mathrm{M} 2^{\circ}$, the asparagine residue is replaced by a serine.

\section{Gene Expression Profile of the Tick $\alpha_{2} M-F$}

To examine transcriptional profiles of the newly identified genes, we performed tissue-specific RT-PCR using cDNAs prepared from hemocytes, gut, salivary glands and ovaries of semi-engorged I. ricinus females (fig. 2). Tick $A_{2} M s$ and MCRs were the most abundantly expressed genes detected in all tested tissues, with the exception of $A_{2} M 2^{\circ}$, whose expression was not detected in the gut. In contrast, the C3-like and TEP genes displayed a tissue-specific pattern of expression, where C31, C3-2 and C3-3 were mainly transcribed in hemocytes and TEP transcripts were detected only in the salivary glands.

\section{Proteins of the Tick $\alpha_{2} M-F$ Are Required for an \\ Efficient Phagocytosis of Bacteria}

We next tested whether tick $\alpha_{2} \mathrm{M}-\mathrm{F}$ proteins are involved in the phagocytosis of bacteria by the tick hemocytes. We first examined requirement of the active TE bond for phagocytosis. To this end, we compared phagocytic indexes of bacteria incubated with hemolymph before and after methylamine treatment. Methylamine readily reacts with TE bonds and inactivates all TEPs potentially present in the hemolymph. Hemolymph collected from semi-engorged ticks was pretreated with methylamine, incubated with bacteria, and phagocytosis was visualized by indirect immunofluorescence using bacteria-specific antibodies [22]. The phagocytic index was determined as a percentage of phagocytic hemocytes. Phagocytosis was tested for cultured live Gram-negative C. indologenes, E. coli, B. burgdorferi and Gram-positive $S$. aureus. The methylamine treatment caused a significant decrease in the phagocytosis of $C$. indologenes and E. coli (fig. 3a). In contrast, phagocy tosis of B. burgdorferi and $S$. aureus was not affected, suggesting that their engulfment was independent on the $\alpha_{2} \mathrm{M}-\mathrm{F}$ members containing active TE.

Tick Thioester-Containing Proteins

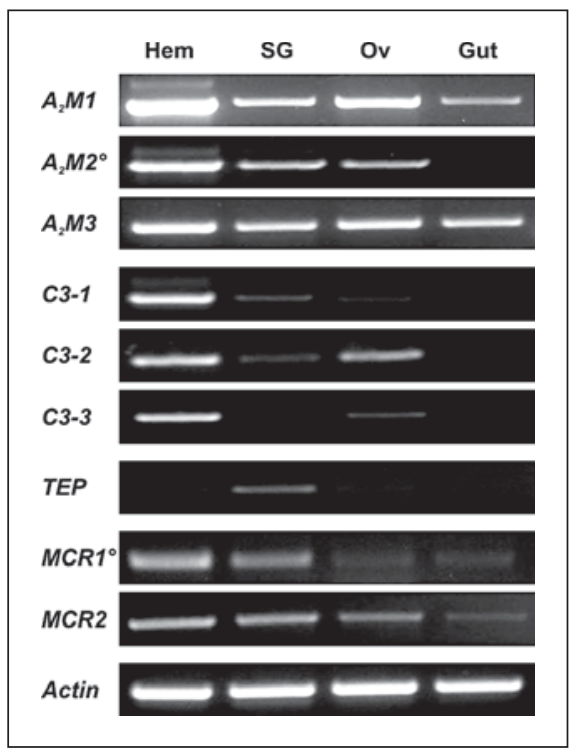

Fig. 2. Transcription profile of tick $\alpha_{2} \mathrm{M}$ family genes. RT-PCR was performed on cDNAs of tissues dissected from semi-engorged females of $I$. ricinus. Hemocytes (Hem), salivary glands (SG), ovaries (Ov) and gut (Gut) are shown. The same number of amplification cycles (30) was used for all genes. Actin served as a loading control.

The role of individual $\alpha_{2} \mathrm{M}-\mathrm{F}$ in phagocytosis of $C$. indologenes and E. coli was further examined by RNAi-mediated gene silencing. Unfed adult females were injected with gene-specific dsRNAs and one day later fed on guinea pigs. For each gene, hemolymph from $25 \mathrm{semi-}$ engorged ticks was pooled and incubated with bacteria. Ticks injected with $d s G F P$ served as a negative control for dsRNA injection. The phagocytic index was determined as described above. The relative phagocytosis was expressed as a ratio of the phagocytic index in the experimental group to the phagocytic index in the $d s G F P$ control in each respective experiment. In the $d s G F P$ control experiments, $21.6 \%( \pm 5 \%)$ of tick hemocytes phagocytosed $C$. indologenes. Phagocytosis of this bacterium was significantly decreased by silencing of $A_{2} M 1$ and $A_{2} M 2^{\circ}$. However, the most profound effect, reaching almost the methylamine treatment levels, was observed upon C3-3 knockdown. Silencing of other $\alpha_{2}$ M-F genes also affected phagocytosis, but the levels of reduction, except for the C3-1, were not statistically significant (fig. 3b). The phagocytic index for $E$. coli in the $d s G F P$ control was in the average of $33.7 \%$ ( $\pm 6 \%)$. Silencing of TEP and C3-3 significantly reduced the phagocytic index to the levels of methylamine treatment (fig. 3c). Our results demonstrate

J Innate Immun 2011;3:623-630 


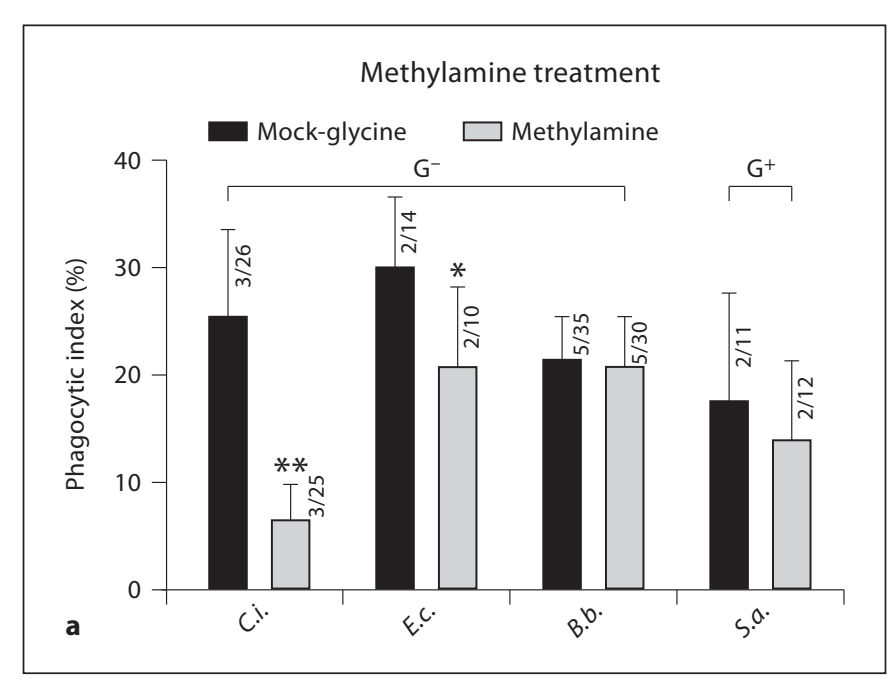

Fig. 3. Phagocytosis of bacteria by tick hemocytes. Hemolymph collected and pooled from 25 semi-engorged females was incubated with indicated bacteria for $1 \mathrm{~h}$. The phagocytic index was determined as a ratio of phagocytic versus nonphagocytic hemocytes. a Effect of methylamine pre-treatment of the hemolymph (ME; inhibition of TEPs) on phagocytosis of C. indologenes (C.i.), B. burgdorferi (B.b.), E. coli (E.c.), and S. aureus (S.a.). Gram-positive bacteria $\left(\mathrm{G}^{+}\right)$and Gram-negative bacteria $\left(\mathrm{G}^{-}\right)$are shown. Glycine was used as a mock control. b Effect of RNAi silencing of $\alpha_{2} \mathrm{M}-\mathrm{F}$ genes on phagocytosis of $C$. indologenes by tick hemocytes. c Effect of RNAi silencing of $\alpha_{2} \mathrm{M}-\mathrm{F}$ genes on phagocytosis of $E$. coli by tick hemocytes. Dashed line indicates the average level of phagocytosis after methylamine pretreatment. The numbers next to the error bars indicate the number of independent experiments (ME treatments or RNAi knockdowns) and the number of phagocytic indexes counts. ${ }^{*} \mathrm{p}<0.01 ;{ }^{* *} \mathrm{p}<0.001$ versus GFP controls.

involvement of 4 of 9 tick $\alpha_{2} \mathrm{M}$-F proteins in phagocytosis of Gram-negative bacteria, and reveal their nonredundant roles in tick immunity.

\section{Discussion}

The ever-increasing data from genome sequencing projects offer novel insights into the evolution of protein families. Previously, $\alpha_{2}$ Ms and C3 proteins have been found in such diverse organisms as vertebrates, hagfish, sea anemones and sea urchins, and were believed to represent two evolutionarily ancient branches of $\alpha_{2} \mathrm{M}-\mathrm{F}[12$, 27]. The common knowledge based predominantly on biochemical analyses ascribed functions of pan-protease inhibitors to $\alpha_{2} \mathrm{Ms}$ and of opsonins to C3 proteins. More
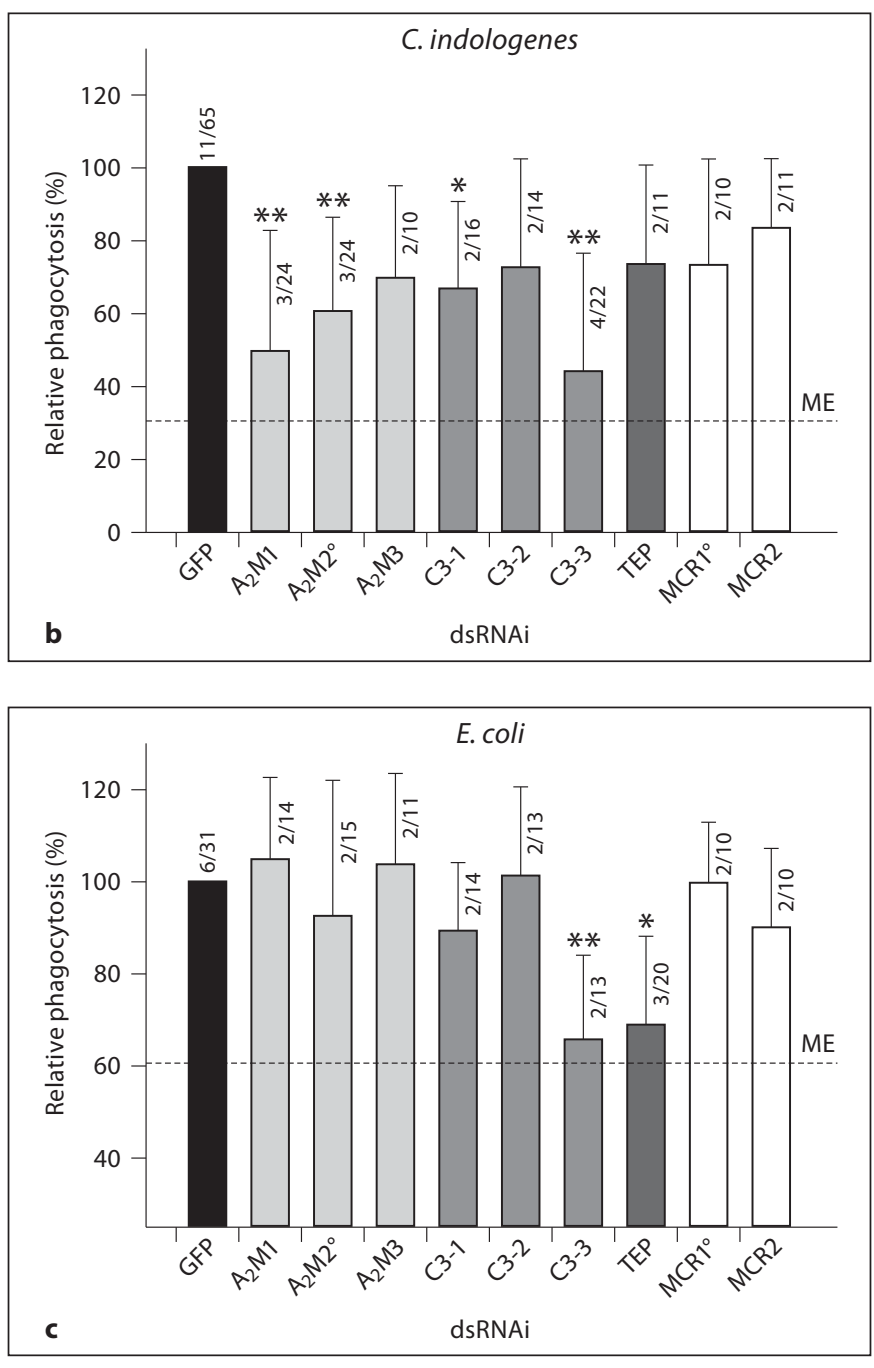

recently, it became clear that dipteran insects lack $\alpha_{2} \mathrm{Ms}$ and C3 molecules, and instead use a novel third branch of $\alpha_{2}$ M-F proteins, called TEPs, to defend themselves against a wide range of pathogens [11]. Here, by a functional analysis of the tick genome, we demonstrate that ticks, which are chelicerate arthropods, possess members of all four $\alpha_{2} \mathrm{M}-\mathrm{F}$ classes, suggesting that a full set of $\alpha_{2} \mathrm{M}-\mathrm{F}$ proteins was present in the arthropod ancestor. During evolution, invertebrates must have lost some branches of the $\alpha_{2} \mathrm{M}-\mathrm{F}$ family, with the most striking example of C. elegans, which has only one representative TEP in its genome. Is loss of the family members translated into the loss of particular functions, and can other members of the family functionally substitute for the missing proteins and perform their functions? In insects, the functions of TEPs, which are organized in distinct species-specific clusters, 
seem to differ from one species to another. In fact, only one group of $\alpha_{2} \mathrm{M}-\mathrm{F}$ proteins, the MCR proteins, seems to be conserved and represented by an orthologous member in all insect species sequenced so far. Ticks have two members of this group, and our phylogenetic analysis suggests that arthropod MCRs form an independent group within $\alpha_{2} \mathrm{M}-\mathrm{F}$. Our results show that tick $\alpha_{2} \mathrm{M}-\mathrm{F}$ proteins form four phylogenetically, structurally and functionally distinct classes. Until now, members of all $\alpha_{2} \mathrm{M}-\mathrm{F}$ groups have never been observed in a single organism. Therefore, ticks represent a formidable model to study the evolution of $\alpha_{2} \mathrm{M}-\mathrm{F}$ in metazoan phyla.

We have previously reported that phagocytosis of the tick pathogen C. indologenes in I. ricinus was mediated by the activity of a bacterial secreted metalloprotease and the tick protease inhibitor $\mathrm{A}_{2} \mathrm{M} 1$ [20]. Here we extend our analysis to demonstrate that knockdown of both $\mathrm{A}_{2} \mathrm{M1}$ and $A_{2} M 2^{\circ}$ significantly decreases phagocytosis of $C$. indologenes. However, none of the tick $\alpha_{2} \mathrm{M}$ genes is required for phagocytosis of $E$. coli. These results suggest that in ticks $\alpha_{2}$ Ms may have a dual function or may exploit their protease binding properties for enhancing phagocytosis of protease-secreting bacteria.

Among arthropods, a homolog of the central component $\mathrm{C} 3$ of the vertebrate complement system has been identified only in the horseshoe crab (Chelicerata) [28]. We identified three tick C3-like molecules (C3-1, C3-2, C3-3), which possess domains characteristic of the vertebrate $\mathrm{C} 3$, including the crucial anatophylatoxin and the C-terminal NTR/complement C345C domains. Our results now show that one of the $\mathrm{C} 3$ proteins $(\mathrm{C} 3-3)$ is absolutely required for phagocytosis of Gram-negative $C$. indologenes and E. coli.

TEPs form expanded families in dipteran insects and comprise for example 6 members in Drosophila and 15 members in the mosquito A. gambiae [11]. The presence of a TEP-like molecule in the tick genome (TEP) suggests that arthropod TEPs have individualized early in animal evolution from the other members of the $\alpha_{2} \mathrm{M}-\mathrm{F}$.

MCR-like proteins have been previously described only in insects [24]. In addition to the typical $\alpha_{2} \mathrm{M}$ or TEP-like structures, MCRs display an LDLa domain. This domain is found in a number of vertebrate lipoprotein receptors, like LDL receptor or $\alpha_{2} \mathrm{M}$ receptor [29], but also in C9 complement component, involved in the formation of the membrane attack complex [13]. The exact function of this domain in the insect MCRs is unknown. Phylogenetic analysis clusters tick MCR1 and MCR2 ${ }^{\circ}$ into one clade with insect MCRs and together they form a separate arthropod-specific group within the $\alpha_{2}$ M-F.
Our results did not reveal any significant role for the tick MCRs in the phagocytosis of tested bacteria. A recent report in D. melanogaster suggested a role for MCR (TEP6) in the phagocytosis of yeast [24] by cultured cells, whereas another study demonstrated expression of MCR in the larval imaginal disks [30]. As loss-of-function MCR mutants were larval lethal, the authors proposed that this protein plays a key role in Drosophila development.

Although further studies should evaluate the role of bacterial proteases and tick $\alpha_{2}$ M-F proteins in the phagocytosis of a larger number of bacterial species, the data obtained here suggest that ticks possess a complementlike pathway involving two independent branches, which converge on the C3-3 protein. Indeed, depletion of this protein caused the most massive decrease in phagocytosis of two bacterial species by tick hemocytes. It is tempting to propose that $\mathrm{A}_{2} \mathrm{Ms}$ and TEP have evolved to interact with different classes of pathogens. In this scenario, $\mathrm{A}_{2} \mathrm{M}$ will be targeted to protease-secreting bacteria, whereas TEP will interact with other Gram-negative bacteria. These initial interactions will lead to the activation of the central C3-3 component.

Finally, interactions of tick $\alpha_{2} \mathrm{M}-\mathrm{F}$ proteins and other pathogens have not been addressed by this study. Mosquito TEP1, an ortholog of the tick TEP, regulates Plasmodium development by binding to the surface of ookinetes and initiating their lysis. Depletion of TEP1 in mosquitoes by RNAi dramatically impairs efficiency of Plasmodium killing $[16,17]$. It would be of enormous interest to examine roles of the tick TEP in transmission of apicomplexan protozoa of the genera Babesia or Theileria, close relatives of Plasmodium. Tick-borne diseases caused by these parasites devastate livestock production worldwide and are also of medical importance as causative agents of human infections. Understanding the molecular mechanisms that shape efficient parasite killing could provide new concepts for blocking the transmission of babesiosis and theileriosis in the field.

\section{Acknowledgments}

We thank Prof. Jules A. Hoffmann for constructive discussions and critical comments on the manuscript. This work was supported by grant No. P506/10/2136 to P.K. from the Grant Agency of the Czech Republic and by the Research Center LC06009 and Research projects Z60220518 and MSMT6007665801 from the Ministry of Education, Youth, and Sports of the Czech Republic. O.H. is supported by the Long-Term EMBO fellowship. E.A.L. is an international scholar of the Howard Hughes Medical Institute. 


\section{References}

$>1$ de la Fuente J, Estrada-Pena A, Venzal JM, Kocan KM, Sonenshine DE: Overview: ticks as vectors of pathogens that cause disease in humans and animals. Front Biosci 2008;13: 6938-6946.

2 Sonenshine DE: Biology of Ticks. New York, Oxford University Press, 1991.

$>3$ Hovius JW, van Dam AP, Fikrig E: Tick-hostpathogen interactions in lyme borreliosis. Trends Parasitol 2007;23:434-438.

4 Kocan KM, de la Fuente J, Blouin EF: Advances toward understanding the molecular biology of the Anaplasma-tick interface. Front Biosci 2008;13:7032-7045.

$\checkmark 5$ Chauvin A, Moreau E, Bonnet S, Plantard O, Malandrin L: Babesia and its hosts: adaptation to long-lasting interactions as a way to achieve efficient transmission. Vet Res 2009; 40:37.

6 Bishop R, Musoke A, Skilton R, Morzaria S, Gardner M, Nene V: Theileria: life cycle stages associated with the ixodid tick vector; in Bowman AS, Nuttall PA (eds): Ticks: Biology, Disease and Control. New York, Cambridge University Press, 2008, pp 308-324.

7 Sonenshine DE, Hynes WL: Molecular characterization and related aspects of the innate immune response in ticks. Front Biosci 2008; 13:7046-7063.

$>8$ Nene V: Tick genomics - coming of age. Front Biosci 2009;14:2666-2673.

$>9$ de la Fuente J, Kocan KM, Almazan C, Blouin EF: RNA interference for the study and genetic manipulation of ticks. Trends Parasitol 2007;23:427-433.

10 Hajdusek O, Sojka D, Kopacek P, Buresova V, Franta Z, Sauman I, Winzerling J, Grubhoffer L: Knockdown of proteins involved in iron metabolism limits tick reproduction and development. Proc Natl Acad Sci USA 2009;106:1033-1038.

-11 Blandin S, Levashina EA: Thioester-containing proteins and insect immunity. Molecular Immunology 2004;40:903-908.
12 Armstrong PB: Role of $\alpha 2$-macroglobulin in the immune response of invertebrates. In vertebr Surviv J 2010;7:165-180.

13 Ricklin D, Hajishengallis G, Yang K, Lambris JD: Complement: a key system for immune surveillance and homeostasis. Nat Immunol 2010;11:785-797.

14 Levashina EA, Moita LF, Blandin S, Vriend G, Lagueux M, Kafatos FC: Conserved role of a complement-like protein in phagocytosis revealed by dsRNA knockout in cultured cells of the mosquito, Anopheles gambiae. Cell 2001;104:709-718.

15 Moita LF, Wang-Sattler R, Michel K, Zimmermann T, Blandin S, Levashina EA, Kafatos FC: In vivo identification of novel regulators and conserved pathways of phagocytosis in A. gambiae. Immunity 2005;23:65-73.

16 Blandin S, Shiao SH, Moita LF, Janse CJ, Waters AP, Kafatos FC, Levashina EA: Complement-like protein TEP1 is a determinant of vectorial capacity in the malaria vector Anopheles gambiae. Cell 2004;116:661-670.

17 Blandin SA, Marois E, Levashina EA: Antimalarial responses in Anopheles gambiae: from a complement-like protein to a complement-like pathway. Cell Host Microbe 2008; 3:364-374.

18 Kopacek P, Weise C, Saravanan T, Vitova K, Grubhoffer L: Characterization of an $\alpha$-macroglobulin-like glycoprotein isolated from the plasma of the soft tick Ornithodoros moubata. Eur J Biochem 2000;267:465-475

19 Saravanan T, Weise C, Sojka D, Kopacek P. Molecular cloning, structure and bait region splice variants of $\alpha 2$-macroglobulin from the soft tick Ornithodoros moubata. Insect Biochem Mol Biol 2003;33:841-851.

20 Buresova V, Hajdusek O, Franta Z, Sojka D, Kopacek P: IrAM-an $\alpha 2$-macroglobulin from the hard tick Ixodes ricinus: characterization and function in phagocytosis of a potential pathogen Chryseobacterium indologenes. Dev Comp Immunol 2009;33:489498.

$>21$ Doan N, Gettins PG: Human $\alpha 2$-macroglobulin is composed of multiple domains, as predicted by homology with complement component C3. Biochem J 2007;407:23-30.
22 Buresova V, Franta Z, Kopacek P: A comparison of Chryseobacterium indologenes pathogenicity to the soft tick Ornithodoros moubata and hard tick Ixodes ricinus. J Invertebr Pathol 2006;93:96-104.

23 Sojka D, Hajdusek O, Dvorak J, Sajid M, Franta Z, Schneider EL, Craik CS, Vancova M, Buresova V, Bogyo M, Sexton KB, McKerrow JH, Caffrey CR, Kopacek P: IrAE: An asparaginyl endopeptidase (legumain) in the gut of the hard tick Ixodes ricinus. Int J Parasitol 2007;37:713-724.

24 Stroschein-Stevenson SL, Foley E, O’Farrell $\mathrm{PH}$, Johnson AD: Identification of Drosophila gene products required for phagocytosis of Candida albicans. PLoS Biol 2006;4:e4.

25 Law SK, Dodds AW: The internal thioester and the covalent binding properties of the complement proteins C3 and C4. Protein Sci 1997;6:263-274.

26 Sottrup-Jensen L, Hansen HF, Pedersen HS, Kristensen L: Localization of epsilon-lysylgamma-glutamyl cross-links in five human $\alpha$ 2-macroglobulin-proteinase complexes. Nature of the high molecular weight crosslinked products. J Biol Chem 1990;265: 17727-17737.

27 Nonaka M, Kimura A: Genomic view of the evolution of the complement system. Immunogenetics 2006;58:701-713.

28 Zhu Y, Thangamani S, Ho B, Ding JL: The ancient origin of the complement system. EMBO J 2005;24:382-394.

29 Kristensen T, Moestrup SK, Gliemann J, Bendtsen L, Sand O, Sottrup-Jensen L: Evidence that the newly cloned low-density-lipoprotein receptor related protein (LRP) is the $\alpha 2$-macroglobulin receptor. FEBS Lett 1990;276:151-155.

30 Bou Aoun R, Hetru C, Troxler L, Doucet D, Ferrandon D, Matt N: Analysis of thioestercontaining proteins during the innate immune response of Drosophila melanogaster. J Innate Immun 2011;3:52-64. 